\title{
A Gestão de Design em uma empresa do ramo de chocolates: proposição de ações de Gestão de Design estratégico com base em diagnóstico para consolidação da marca
}

\author{
The Design Management in a company of chocolates: proposing actions in Management of \\ Estrategic Design based in diagnosis to brand consolidation
}

\author{
MACRI, Renato Domingues Záccaro \\ Especialista; Universidade Estadual de Londrina \\ renatodg@uel.br \\ MARTINS, Rosane Fonseca de Freitas \\ Dra. Universidade Estadual de Londrina \\ rosane@uel.br
}

\begin{abstract}
Resumo
Este artigo tem como objetivo diagnosticar a situação de uma empresa do ramo de chocolates em relação à sua marca e propõe algumas ações básicas de Gestão de Design e outras de Marketing e, assim, contribuir para a sua consolidação no mercado. Como metodologia, possui natureza exploratória cujo delineamento é um estudo de caso. Como resultado, obtém uma proposição de ações de Gestão de Design e Marketing baseadas no diagnóstico aplicado e propõe dois protocolos para a posterior análise dos resultados de tais ações: Análise de Gestão Aplicada e BSC.
\end{abstract}

Palavras Chave: Diagnóstico; Gestão de Design; Branding.

\begin{abstract}
This article aims to diagnose the status of a branch company of chocolates referring to her brand, offering some basic actions of Marketing and deeper ones in Design Management and so contribute to its consolidation in the market. As methodology it has an exploratory nature whose direction is a case study. As a result, it obtains a proposal of actions of Marketing and Design Management based on the diagnosis and proposes two protocols used in the subsequent analysis of the results of such actions: Analysis of Applied Management and BSC.
\end{abstract}

Keywords: Diagnosis; Management Design; Branding.

\section{Introdução}

O presente artigo visa registrar uma experiência de Gestão de Design em uma empresa comercial do ramo de chocolates. Direciona-se à aplicação de um diagnóstico, importante recurso na construção e consolidação da marca para se detectar, a partir da visão empírica da diretoria, a realidade atual desta empresa no mercado, conduzindo-a a um olhar mais apurado em relação a si mesma, seus clientes, fornecedores e concorrentes. 
Em uma abordagem inicial, pode-se perceber por parte da proprietária uma latente expectativa e uma urgente necessidade de se agregar predicados como força corporativa, renome e consistência mercadológica à marca de sua empresa. Em outras palavras, ela declara sentir falta de ações de marketing eficazes e de um padrão visual coeso que possa agregar força, expressão, peso e unidade visual (padrão) que contribuam para a fixação de sua marca no mercado. Apesar da total confiança na excelência da qualidade de seus produtos e serviços, que já possuem boa aceitação por parte tanto dos consumidores efetivos quanto eventuais, percebe-se, de fato, a falta de uma projeção mercadológica mais efetiva e abrangente e de uma imagem corporativa cuja consistência valorize ainda mais seus atributos e valores.

Diante do problema sinteticamente apresentado, este artigo tem como objetivo geral propor ações para se implementar a Gestão de Design (GD) em uma empresa do ramo de chocolates visando a consolidação de sua marca e sugerir procedimentos para análise de resultados e manutenção do plano de GD. Como objetivos específicos, visa aplicar um briefing tradicional e uma ferramenta de diagnósticos na empresa (neste artigo identificada como "Empresa X") para a captação de dados; a partir do panorama detectado, sugerir ações nas esferas do Design e do Marketing orientadas à consolidação da marca e à promoção de seus produtos e serviços; e, por fim, propor um sistema de análise de resultados aplicável após a implementação das ações com o objetivo de avaliar a eficiência do plano estabelecido, baseado em um método sugerido por Merino (2008) e pela ferramenta BSC apresentada por Kaplan (1998).

A proposta de ações em Gestão de Design se justifica em função das demandas, potencialidades e carências detectadas na ferramenta de diagnostic, a fim de se corrigir posturas, ratificar eventuais acertos e apontar diretrizes eficazes orientadas à consolidação de sua marca em curto, médio e longo prazo. A Empresa $X$ reconhece fragilidades nas suas bases estratégicas, táticas e operacionais em relação às ações de Marketing e Design que vem desenvolvendo no intento de divulgar e manter a sua marca, e por conseguinte a sua própria imagem, no mercado. A carência de soluções eficazes de diversas dimensões e naturezas para atender às suas demandas, potencialidades e expectativas parece provir, basicamente, de indefinições no seu próprio modo de enxergar-se como organização e também de visualizar as várias instâncias de sua personalidade corporativa em relação a si mesma e ao consumidor. A ferramenta de diagnóstico proposta neste artigo tem a função de detectar os pontos- chaves a serem trabalhados com base em sua realidade, aspirações e necessidades, sejam elas primárias ou secundárias, em curto, médio e longo prazo.

A Empresa $X$ manifesta latente necessidade de consolidar sua marca, intencionando atributos como força, consistência, pregnância e rápida identificação por seu público; também entende que o incremento das vendas acontece na razão direta de seus esforços em publicidade e, consequentemente, na manutenção regular e eficiente de sua imagem no mercado. Por esta razão, ações elementares de marketing são, portanto, imprescindíveis neste processo.

A fundamentação teórica apoia-se em dois grandes pilares: o primeiro traz uma breve descrição sobre a importância da Gestão do Design nas empresas e como ele é essencial em todos níveis organizacionais (estratégicos, tático e operacional); e o segundo aglutina uma visão contemporânea e inovadora de marketing, especificamente em branding (gerenciamento de marcas e processos rompendo antigos paradigmas) e uma das muitas ferramentas estratégicas disponíveis na literatura, o Balanced Sorecard (BSC) selecionada em função de sua aplicação para o objeto de estudo deste artigo. Estas bases teóricas 
oferecem subsídios para que se contemplem na ferramenta de diagnóstico questões que venham auxiliar a tornar-se visível a verdadeira situação da empresa enquanto marca e organização e quais os pontos positivos e negativos que a influenciam no momento presente.

Como metodologia, empregou-se uma pesquisa de natureza exploratória, cujo delineamento foi um estudo de caso, e como estratégias, entrevistas e questionários. Para que posturas, rotinas e procedimentos pautados na Gestão de Design sejam propostos de maneira a se obter a eficácia desejada é preciso, antes de tudo, ter-se em mãos um diagnóstico preciso, cientificamente elaborado e de amplo espectro. Aplica-se então, além do briefing tradicional, uma ferramenta de diagnóstico composta por questões que investigam e trazem à tona opiniões, visões e situações de diversos níveis, com o objetivo de mapear quais são as filosofias de trabalho, as aspirações, como está organizada a estrutura estratégica, tática e operacional da empresa, quais são suas atitudes enquanto estrutura comercial e o quanto estas interferem, de fato, em seus negócios.

Como resultado, a aplicação de um diagnóstico detalhado com base cientifica possibilitou a proposição de ações administrativas e de Gestão de Design que devem conduzir para o avivamento esperado para a marca. E sugere, ainda, o monitoramento da eficácia destas ações via Análise de Gestão Aplicada e BSC.

\section{A Gestão de Design como estratégia organizacional}

Inicialmente, deve-se partir de um referencial teórico para se observar a importância da contribuição do design nos diferentes níveis administrativos e processuais de uma empresa. Segundo Martins e Merino (2008, p. 60), apoiados no raciocínio de Bahiana (1998):

O processo formativo do Design deveria propiciar uma visão sistêmica do processo de desenvolvimento de projetos, inicialmente sob uma perspectiva operacional do saber fazer e complementando com uma visão estratégica. Esta última, é a que possibilitará ações de Gestão do Design, e uma aproximação mais eficaz junto às outras áreas afins. O foco na solução é mais um paradigma que deve ser observado, praticado e incorporado na atividade, partindo do pressuposto de que o problema é a origem dos projetos).

O design refere-se, portanteo, a todos os aspectos funcionais, ergonômicos e visuais de um produto, intrínsecos em fatores como qualidade de uso, busca da nova forma, melhoria nos processos de produção, compromisso ambiental além de priorizar as relações estéticas, de conforto, segurança e satisfação que mantém com seu público, agregando diferencial competitivo, adequando necessidades por parte do mercado consumidor e auxiliando na configuração da capacidade de produção esperada por parte da empresa. Agrega valor para quem o produz e também para quem o consome, por isso possui um caráter fundamentalmente estratégico.

O design traz benefícios presentes na imagem da empresa, tornando-a inovadora, coerente com as novas tendências mundiais, e permitindo a rápida associação do produto com a sua imagem. Outra vantagem para a empresa é a otimização de custos, por usar formas mais eficientes, matéria-prima e processos de fabricação adequados, evitando desperdícios. Também, um bom projeto facilita as vendas no exterior, aumentando a 
competitividade frente a outras empresas, que também utilizam o design como fator constante de inovação.

Até mesmo quando as ofertas parecem as mesmas, os consumidores respondem de forma diferente à imagem da empresa ou marca. Imagem, neste contexto, é a maneira como o público percebe a empresa e/ou seus produtos. É conduzida por todos os tipos de mídia e leva tempo para ser implantada na mente do consumidor, transmite poder emocional e uma mensagem que estabelece características e valores aos produtos de maneira distintiva. A sua identidade se molda nas várias formas que uma empresa adota para identificar ou posicionar seu produto e deve fazer parte de todas as comunicações da empresa e mostrarse repetidamente.

A Gestão de Design é uma ferramenta que integra as funções operacionais do design em todos os setores da empresa, visando atingir os objetivos traçados e propiciar a percepção de uma imagem positiva. Como comunica os valores e a filosofia da empresa, deve estabelecer uma política que se manifeste por meio de um design corporativo consistente, atingindo, assim, uma unidade em seu discurso, facilidade na identificação de sua mensagem e possibilitando índices de memorização que favorecem o comportamento de troca. Para Mozota (2002), as empresas que apresentam as características que mais favorecem o design são as que se adiantam em relação a mudanças ou pressões do seu ambiente de atuação, e possuam uma cultura propícia à inovação.

Segundo o Centro Português de Design (1997), o campo de atuação do design transcende a criação de peças gráficas e produtos como elementos isolados, passando a ser parte de um sistema e consolidando-se como um processo de gestão.

\section{Marketing}

Segundo Kotler e Amostrong (1997), até há bem pouco tempo, as vendas e a propaganda caracterizavam o marketing, e atualmente são apenas a "ponta do iceberg". As peças do mix de mkt (conjunto de ferramentas de marketing que operam juntas para satisfazer necessidades de clientes e construir relacionamentos com eles), que são os quatro " $p$ "s, e que também o definiam até pouco tempo atrás, hoje operam na criação de valor e estão diluídos entre os 5 principais conceitos de marketing, que são: criação de valor para os clientes para capturar, em troca, valor dos clientes; construção e gerenciamento de marcas fortes e criadoras de valor; administração do retorno sobre o marketing para capturar o valor da marca; domínio das novas tecnologias de marketing e; o marketing socialmente responsável ao redor do mundo.

Os autores dizem que a análise dos 4 p's não é mais suficiente. O marketing, hoje, busca pelo diferencial competitivo, por agregar valor, por valorizar a marca junto ao mercado, pelo equilíbrio dos 4 p's e por aumentar o market share (fatia de Mercado), que se consegue por meio da busca de inovação (P\&D), segmentação (o consumidor decide) e pela distribuição geográfica (busca de novos mercados). A comunicação e os 4 p's atuam em nível tático, e segmentação, alvo e posicionamento (e depois as $4 p^{\prime} s$ ), compõem o marketing estratégico.

Para Kotler e Amostrong (1997), Marketing é administrar relacionamentos lucrativos com os clientes, e seus principais objetivos são: atrair novos clientes prometendo-lhes valor superior, e manter e cultivar os clientes atuais, proporcionando-lhes satisfação. 
Drucker (1987) diz, ainda, que o objetivo do marketing é tornar a venda desnecessária. É conhecer o consumidor tão bem que o produto ou empresa se venda sozinho. Assim como o Design, é uma ferramenta estratégica competitiva, com a distinção de que o Design é um importante recurso para proposição e pregnância de valores. É centrado, portanto, na criação de valor para o cliente e na construção de valor lucrativo com ele. Para isso deve-se, então, entender o que se deseja, quais as reais necessidades, definirse os mercados-alvos e desenvolver uma proposição de valor para estas finalidades.

A liderança da marca: o paradigma emergente

Como os objetos tratados neste estudo de caso circundam a marca da empresa $\mathrm{X}$ e seus valores, é importante se delimitar o conceito de "marca" e sob quais aspectos ela deve ser administrada. Dentre os cinco principais conceitos de marketing apresentados por Kotler e Amstrong (2007), três se referem prioritariamente à marca: criação de valor para os clientes para capturar, em troca, valor dos clientes; construção e gerenciamento de marcas fortes e criadoras de valor; administração do retorno sobre o marketing para capturar o valor da marca. Isto demonstra que a marca deve ser considerada um importante foco de atenções por parte dos empresários.

Aacker (2007), sugere uma visão diferenciada, inovadora e contemporânea para gestão de marcas. Romper paradigmas é a essência deste modo de pensar e agir e tal premissa tende a revolucionar um modo linear e restrito de se enxergar uma empresa e seus negócios, principalmente como ela fundamenta sua conduta na relação marca-produtomercado. "O gestor no paradigma de liderança da marca é estratégico e visionário em vez de tático e reativo." (AAKER, 2007, p. 19).

A manutenção de uma marca no mercado, portanto, requer um cuidado mais amplo e sistêmico de seu gestor, que se vê motivado a abandonar a antiga postura tática e reativa para atuar de uma forma mais ampla, tornando-se um profissional mais estratégico e visionário. O objetivo é tomar controle da marca estrategicamente, e assumir um papel estratégico significa que o gestor da marca precisa estar envolvido ao criar a estratégia do negócio em vez de simplesmente implementá-la. "A estratégia do negócio deve ser a primeira condutora da estratégia da marca e ambas devem refletir a mesma visão estratégica e cultura corporativa."(AAKER, 2007, p. 19). Sustenta, ainda, que a identidade da marca deve estar em consonância com as posturas estratégicas da empresa a que pertence, pois de nada adianta desenvolver ações para a gestão da marca em função de estratégias que não dão lucro ou agregar a ela promessas vazias.

Aacker (2007), apresenta alguns pontos que norteiam a ação do gestor da marca no plano estratégico. Primeiramente chama a atenção para a importância do perfil profissional do gestor, que, até há algum tempo, era normalmente uma pessoa inexperiente e substituída a cada dois ou três anos. No paradigma de liderança, seu papel é peça-chave na área de marketing. "Para as organizações conduzidas pelo marketing, onde há um talento de marketing no topo, o gestor da marca é o CEO." (AAKER, 2007, p. 19)

Outro ponto a ser destacado é o foco na equidade da marca. A equidade é um valor trabalhado desde o plano estratégico, que traz resultados consistentes como vantagens competitivas e lucratividade em longo prazo e que deve ser acompanhada de perto pelo principal executivo da organização. A Imagem, por sua vez, é um elemento tático que traz resultados em curto prazo e por esta razão pode ser conduzida confortavelmente por 
especialistas de publicidade e propaganda. No paradigma de liderança então, o objetivo é "construir equidades em vez de simplesmente gerir as imagens da marca." (AAKER, 2007, p.20).

Para Kotler e Amstorng (2007), a equidade da marca é o efeito diferenciado positivo que o conhecimento do nome da marca tem sobre a reação do cliente ao produto ou serviço, e é, portanto, um valor importante a ser ofertado.

Um terceiro ponto é estabelecer proporções de equidades para a marca ao invés de suplementar as proporções que, em curto prazo, dominaram o passado. É melhor projetar um futuro consistente do que remediar o passado recente. As equidades da marca podem ser entendidas como a relação de valores como lealdade, qualidades percebidas e associações, incluindo dimensões como personalidade, características organizacionais e símbolos. A ênfase está no monitoramento dos elementos de identidade da marca que diferenciam e conduzem ao relacionamento consumidor-marca, o que implica uma compreensão aprofundada da marca e do seu relacionamento com seus clientes.

De um foco limitado a um foco amplo: no modelo clássico de uma grande empresa multinacional, o escopo do gestor não se limitava apenas a uma marca somente, mas também a um produto e um mercado. A comunicação era intensamente focada e com menos opções disponíveis e a comunicação interna da marca praticamente ignorada. No paradigma de liderança da marca, as mudanças e os contextos são muito diferentes e a tarefa tem sido expandida. A visão é mais ampla e assim se abre, a todo o momento, novas possibilidades e margens para incrementos e ajustes necessários.

Uma marca pode abranger mais do que um produto ou um mercado. A marca torna-se determinante no mercado e o escopo deste mercado um ponto-chave de gestão. Neste escopo vale expandir a marca por todos os mercados (horizontal e verticalmente) como forma de promovê-la. Logo, o gestor da marca deve administrar uma marca que pode contemplar uma variedade de mercados, produtos e sub-marcas e que às vezes representa uma marca fundamentalmente organizacional.

O gestor de marca deve pensar globalmente e deixar o perfil tático de sua ação para ser, de fato, um líder nas áreas de estratégia e comunicação, acessando uma variedade de veículos de comunicação, incluindo patrocínios, Internet, marketing direto, publicidade e propaganda.

No paradigma de liderança da marca, as dimensões da performance a curto prazo tais como vendas e lucros são substituídas ou aumentadas pela identidade da marca como um condutor da estratégia. A identidade da marca deve especificar o que ela aspira simbolizar e o que ela não quer simbolizar. Com a identidade sob controle, a execução pode tornar-se efetiva.(AAKER, 2007, p. 22).

Desenvolver uma identidade para uma marca depende do entendimento dos clientes, concorrentes e a estratégia do negócio da empresa (Aaker, 2007). Soma-se a isto a consciência de que não há nada mais frustrante para o mercado do que ser estimulado ao consumo de algo e não ser devidamente correspondido.

Balanced Scorecard

Este é um dos instrumentos propostos para uma posterior avaliação das ações propostas neste caso. Para Schimidt (2001), algumas empresas têm conseguido vantagens competitivas por meio de estratégias bastante diversas, como produtos de alta qualidade, boa relação com colaboradores, atendimento aos clientes, entre outras. A contextualização do ambiente empresarial demonstra a necessidade de novas práticas gerenciais capazes de 
criar e, principalmente, manter a vantagem competitiva alcançada. Dentre uma série de ferramentas estratégicas disponiveis na literatura, uma delas aplica-se de forma específica a um dos objetos de estudo deste artigo, o Balanced Scorecard (BSC). Kaplan (1998) sustenta que muitos empresários ainda enxergam a ação básica de administração a ser adotada como forma de aumentar os lucros pautada em antigos paradigmas. Para alguns, a solução é ampliar a participação no mercado. Para outros, aumentar a satisfação do cliente. A maioria concorda que os prazos na entrega deveriam ser reduzidos. A posição reacionária de Kaplan é a de dizer, que antes de tudo, eles deveriam, neste momento, esquecer os lucros, que são, assim como aumento de vendas, consequências diretas da interação positiva de dois fatores: o primeiro advém da cadeia de relações causa-efeito e o segundo da intensidade dos fatores impulsionadores detectados durante a operação e administração de uma empresa.

O BSC é um sistema de avaliação de desempenho empresarial configurado para ser um medidor de desempenho com base em indicadores financeiros e não financeiros. Os indicadores financeiros por si só não são suficientes para servir de parâmetros para a análise da performance de uma empresa porque são geralmente mapeados em curto prazo. O lucro atual não indica, necessariamente, empresa saudável e nem potencial de longevidade no mercado. Pode ser ilusório e volátil. O BSC propõe avaliações financeiras, sobre os clientes, identifica processos internos a serem melhorados, possibilidades de aprendizado e crescimento, analisa investimentos em recursos humanos e sistemas de capacitação. Dando boa visão do futuro e dos caminhos para se chegar a ele, o BSC é um sistema de gestão que busca um bom desempenho em várias dimensões e não apenas no financeiro para assim garantir êxito à empresa, principalmente em longo prazo.

O aprendizado e o crescimento propiciam a melhoria da qualidade da inovação que reflete na construção de um diferencial competitivo mais sólido em longo prazo. Sua principal fonte é o capital humano da empresa. O BSC gera o denominado feedback estratégico, que substitui o antigo sistema vertical descendente, no qual as ordens vinham de cima para baixo e as bases da pirâmide eram apenas executores. Atualmente, toda equipe deve ter grande capacidade intelectual e a compreensão dos objetivos definidos pelo plano estratégico por todos os setores da empresa, a fim de se gerar a produção de ideias e sugestões que contribuem para o êxito do plano. O sistema de feedback sugerido pelo BSC propõe os seguintes resultados:

- Traduzir a estratégia em objetivos e iniciativas específicas (onde e como se quer chegar);

- Planejar;

- Estabelecem-se metas para os anos próximos e sugere os meios para alcançá-los. A cada 03 meses colhe-se os feedbacks para se monitorar os passos da equipe;

- Coletar dados e informações sobre como vai a empresa;

- Checar o rumo traçado;

- Verificar se os processos foram melhorados, criados novos produtos ou serviços e se os funcionários foram treinados adequadamente;

- Checar a própria estratégia para ver se ela ainda é correta;

- Feedback Estratégico: incorpora todo o conhecimento que o pessoal da empresa tem sobre as mudanças no ambiente cognitivo.

Os dados provêm dos denominados "donos de medições", apresentados no quadro a seguir: 


\begin{tabular}{|l|l|}
\hline Financeiro & Medições Financeiras; \\
\hline Marketing & Participação No Mercado E Satisfação Do Cliente; \\
\hline Tecnologia & Desenvolvimento E Lançamento De Novos Produtos; \\
\hline Produção & Qualidade, Custos De Fabricação E Rendimento; \\
\hline Rh & Habilidades, Capacitação E Satisfação Dos Funcionários; \\
\hline Informática & Sistema De Informação \\
\hline
\end{tabular}

Quadro 1 - Donos de medições

Fonte: Kaplan (1998, p. 128).

Os dados são coletados mensalmente e centralizados. As informações vêm de sistemas já existentes na empresa. A abordagem visa simplicidade na lida com as informações.

Kaplan (1998) ressalta que implementar o BSC não é apenas medir resultados financeiros e não financeiros. É vincular estas informações a uma cadeia de relações de causa-efeito. Por exemplo, para melhorar o desempenho financeiro (maior lucro) é preciso ampliar a participação de mercado. Para ampliar a participação do mercado deve-se promover a manutenção regular da satisfação dos clientes. Para isso, um dos caminhos é manter a pontualidade e rapidez na entrega, que é impulsionada pelo setor produtivo devidamente treinado e estimulado. Dando mais um passo neste raciocínio, um setor produtivo bem estimulado e treinado propicia à empresa a possibilidade ampliar sua participação no mercado pois oferece plenas condições para abastecê-lo. Então o ciclo se fecha e se renova, o tempo todo.

\section{Metodologia}

A metodologia trabalhada neste caso fundamenta-se em uma pesquisa exploratória descritiva, cujo delineamento é um estudo de caso que enumera pontos chaves a serem posteriormente trabalhados na empresa. Segundo Yin (2001), no estudo de caso são realizados estudos profundos de um ou poucos objetos, permitindo o conhecimento amplo e detalhado. Trata-se do delineamento mais adequado para a investigação de um fenômeno contemporâneo dentro do seu contexto real, no qual os limites entre o fenômeno e o contexto não são claramente percebidos. Os propósitos podem ser os seguintes, segundo Gil (2002): explorar situações da realidade cujos limites não estão claramente definidos; preservar o caráter unitário do objeto estudado; descrever a situação do contexto em que está sendo feita a investigação; formular hipóteses ou desenvolver teorias; explicar variáveis de determinado fenômeno em situações complexas que não possibilitaram a utilização de levantamentos e experimentos. Visa também, proporcionar uma visão geral do problema ou de identificar possíveis fatores que o influenciam ou que são influenciados por ele.

A estratégia adotada, que consiste de questionários e observações no ponto de venda, reúne informações quantitativas e qualitativas que descrevam as características e procedimentos realizados até o momento, em relação à gestão de sua marca e de seus negócios. Especificamente, a estratégia adotada para a coleta de informações no estudo de caso baseia-se na aplicação das seguintes ferramentas:

A - Briefing: intitulado "briefing padrão", foi elaborado ao longo da trajetória professional dos autores, e baseado em uma adaptação do modelo da Thomas Propaganda \& Associados. Foi realizado por meio de entrevista pessoal com base em questionário orientado à coleta de dados de natureza institucional e comercial, contemplando, também, de forma sucinta, considerações 
preliminares mais específicas da área de Marketing (tais como preferências de consumo de seus clientes, políticas de publicidade e propaganda vigentes, aspirações para o futuro, entre outras).

B - Ferramenta de Diagnóstico: foi aplicado à proprietária da empresa o diagnósico proposto pelo Centro Português de Design (CPD), adaptado por Merino (2008), que é composto basicamente de entrevistas e observações a fim de se obter informações sobre como se articula a marca da empresa, como se realiza pesquisas de opinião, de que maneira vem trabalhando a identidade visual, o quanto conhece de seus concorrentes, como explora seus diferenciais, como gerencia e atende seus clientes potenciais eventuais e efetivos, entre outros.

A metodologia adotada conduziu à definição de um panorama (situação geral e latente da empresa) e a sua análise sugere procedimentos de ordem estratégica, tática e operacional a serem propostos. A seguir apresentam-se as informações obtidas por meio da aplicação do briefing e da ferramenta de diagnóstico.

\section{A Briefing padrão à Empresa $X$}

1. Empresa/ razão social

2. Localização

3. Contato

4. Proprietário (a)

5. Breve histórico (quantos anos de existência, como abriu, o que motivou abrir a empresa)

6. Produção (qual a capacidade de atendimento da loja)

7. Propaganda e promoções anteriores (últimos 12 meses)

1. Que produtos comercializa?

2. Vantagens e desvantagens em relação à concorrência (qualidade,

O quê? design, propaganda anterior) embalagem (apresentação, tamanho), distribuição (preço, organização de vendas)

1. Público alvo - Quem frequenta

2. Classe social deste público

Para quem?

3. Faixa etária

4. Público que mais consome

1. A empresa está sendo induzida, se consolidando ou sendo reativa no mercado?

2. Quando é que as vendas crescem,

Como? diminuem ou se mantém?

3. Qual a proporção de vendas do produto "carro chefe" em relação às
Empresa X Ltda.

Londrina $P R$

Sra. $X$

Sra. X

Existe há 3 anos. Sempre foi atraída pela beleza do chocolate. Começou fazendo e vendendo para os amigos e com o tempo sentiu necessidade de abrir a loja.

A loja tem condições de atender o dobro do público que a frequenta atualmente.

Notas em jornais; receitas na televisão; outdoor.

Cafés, chocolates, embalagens de presente, vinhos.

Possui a vantagem de os produtos serem artesanais, $o$ ponto comercial favorável, opção de montar seu próprio presente, boa aparência das embalagens. Desvantagem no fato de a variedade de chocolates precisar aumentar, assim como a diferenciação dos produtos.

Ambos os sexos, jovens e adultos.

Classe A e B.

20 a 50 anos.

Mulheres, universitárias, recém-formadas e jovens empresárias.

Pouco, poderia ser bem melhor.

Crescem mais na Páscoa, Dia dos Namorados, Natal e Dia das Mães. Diminuem de Agosto a outubro.

No caso de cafés, mais no inverno. O "carro chefe" ainda é a trufa. As épocas são as acima citadas. 
vendas totais da empresa? O que mais vende? Em que época?

4. Quais as marcas concorrentes?

5. O incremento de vendas depende de: encontrar novos consumidores, incentivar consumidores atuais, modificar tendências dos atuais ou induzir consumidores a mudar de marca?

1. Quanto pretende investir?

2. Espera retorno a longo, médio ou Quanto? curto prazo?

3. Resultados esperados
Kopenhagen e Cacau Show.

Induzir consumidores a mudar de marca. Encontrar novos consumidores.

O necessário.

Em médio prazo.

Marca conhecida e reconhecida, com design diferente $e$ compacto. Marketing de peso.

Quadro 2 - Briefing padrão aplicado na Empresa X.

\section{B Diagnóstico}

A seguir, foi aplicada uma ferramenta de diagnóstico proposta pelo CPD e adaptada por Merino (Merino, 2008), constituída de 7 indicadores (questões dissertativas): intenção, objetivos esperados pela empresa, informacoes gerais, mercado, especificações, processos produtivos, custos, e oportunidades e restricoes, cujosresulatos sao descritos abaixo.

\section{Intenção (Definição):}

- Incremento na força da marca e aperfeiçoamento da identidade visual de uma loja de produtos base de chocolate e serviços de cafeteria.

\begin{tabular}{|l|l|}
\hline $\begin{array}{l}\text { Objetivos esperados pela } \\
\text { empresa }\end{array}$ & $\begin{array}{l}\text { 10 Reposicionar sua marca no mercado; } \\
\text { 2o Atualizar sua identidade visual; } \\
\text { 3o Sugerir ações de Design como parâmetros para a manutenção regular e efetiva } \\
\text { de seus valores e conceitos diante de si própria e do mercado; } \\
\text { 4o Implementar um sistema de avaliação e controle de seus processos operacionais } \\
\text { de comunicação com o mercado. }\end{array}$ \\
\hline $\begin{array}{l}\text { Melhorias que pretende } \\
\text { para seus produtos/ }\end{array}$ & $\begin{array}{l}\text { Há uma latente e urgente necessidade de predicados como força corporativa, } \\
\text { renome e consistência mercadológica. Em outras palavras, ela declara que sente } \\
\text { falta de ações de marketing eficazes e de um padrão visual coeso que possa agregar } \\
\text { força, expressão, peso, unidade e fixação à sua marca no mercado. Ressalta que tem } \\
\text { total confiança na excelência da qualidade de seus produtos e serviços que possuem } \\
\text { ótima aceitação pelos consumidores efetivos e eventuais, mas percebe a falta de } \\
\text { projeção mercadológica e de uma imagem consistente que valorize seus atributos }\end{array}$ \\
\hline
\end{tabular}

Quadro 3 - Intenção - Incremento na força da marca

\section{Informações gerais:}

- Antecedentes do produto / serviço e produtos / serviços atuais

\begin{tabular}{l|l}
\hline Atividade da empresa & Empresa que atua no comércio, com loja no centro da cidade de Londrina
\end{tabular} (breve descrição) $\mathrm{PR}$, situada em uma de suas principais avenidas. Existe há dois anos, possui como equipe a proprietária e duas auxiliares que executam tarefas como atendimento a clientes, manipulação de produtos e serviços gerais. Comercializa confeitos de chocolate de fabricação própria com matériasprimas nacionais e importadas (predominantemente belgas) ou industrializados (nacionais e importados). Oferece cafés especiais do Brasil (gourmet), pães de queijo, tortas, shakes e capuccinos, com possibilidade de degustar os produtos de chocolate no local, levá-los para posterior consumo ou ainda presentear com estes. O ponto comercial possui algumas mesas e 


\begin{tabular}{|l|l|}
\hline & $\begin{array}{l}\text { cadeiras para a recepção e acolhimento de clientes, decoração favorável ao } \\
\text { consumo e aos serviços, música ambiente e sistema de acesso à internet por } \\
\text { rede sem fio (wi-fi zone). }\end{array}$ \\
\hline $\begin{array}{l}\text { Relação de produtos / } \\
\text { serviços atuais (produtos } \\
\text { que fabrica) }\end{array}$ & $\begin{array}{l}\text { Próprios: Bombons, trufas, barras de chocolate, frozens, tortas salgadas e } \\
\text { doces, bolos, biscoitinhos e empadas. Na cafeteria pode-se encontrar: cafés } \\
\text { expressos, capuccinos, sucos, refrigerantes e águas minerais. } \\
\text { Industriais: chocolates nacionais importados, como belgas }\end{array}$ \\
\hline $\begin{array}{l}\text { Características que } \\
\text { fizeram triunfar e/ou } \\
\text { fracassar os produtos / } \\
\text { serviços }\end{array}$ & $\begin{array}{l}\text { Triunfar: excelente qualidade das matérias-primas, know-how da } \\
\text { proprietária no ramo (18 anos), excelente localização do ponto, foco no } \\
\text { público de classes A e B, bom atendimento e decoração da loja. } \\
\text { Fracassar (estagnação das vendas): sazonalidade do consumo, baixo fluxo de } \\
\text { visitas diárias, falta de divulgação eficiente, pouco investimento em } \\
\text { publicidade. }\end{array}$ \\
\hline
\end{tabular}

Quadro 4 - Informações gerais - antecedentes do produto

- Posicionamento do produto / serviço quanto aos demais / família da mesma empresa Produtos com Identidades visuais divergentes: os produtos não mantém entre si uma unidade visual, possuindo discrepâncias consideráveis nas suas embalagens.

Quadro 5 - Informações gerais - posicionamento do produto

\section{- Produtos / serviços da concorrência}

Características e vantagens que distinguem os concorrentes
Seus concorrentes diretos (outras marcas de chocolates) possuem renome positivo e solidez de mercado. Uma delas orienta seus produtos a públicos de classe B e C, com chocolates que, segundo a proprietária da Empresa $X$, deixam a desejar no quesito qualidade mas que é bem estruturada na questão "logística" e trabalha muito bem a sua marca e a manutenção da sua imagem no mercado. No setor de cafeteria, acredita que os pontos concorrentes, embora setorialmente espalhados e bem distribuídos, oferecem considerável grau de competitividade gerando certo "incômodo". Atribui o baixo índice de procura pelos cafés à desinformação do público em relação à loja e aos produtos/ serviços que oferece, além da falta de uma cultura local de se consumir café primando, essencialmente, a degustação. Seu diferencial perante os concorrentes é a exclusividade de venda de chocolates belgas artesanalmente manipulados e a consultoria no momento da compra (principalmente na escolha de presentes).

Quadro 5-Informações gerais - produtos

\section{Mercado}

- Utilizador do produto

Descrição do utilizador e/ou comprador e/ou consumidor

Necessidades do utilizador e suas expectativas sobre o produto

Qualidades mais apreciadas do produto

Uso do produto / possíveis usos inadequados
Objetivo da loja: Enfatizar o atendimento à seguinte faixa: classes sociais $\mathrm{A} e$ $B$, ambos os sexos, jovens universitários (aproximadamente 70\%), recém formados e adultos empresários.

O público da "Empresa X", segundo a proprietária parece não se ater ao quesito preço desde que o produto adquirido tenha a qualidade esperada. As mulheres consomem mais chocolates e os homens, cafés e têm o hábito de presentear as esposas ou namoradas

Novidades, variedade de artigos, padrão de qualidade e sabor tanto no café enquanto matéria-prima quanto na maneira de prepará-lo e servi-lo; atmosfera do ponto, ineditismo, sabor e origem do chocolate, bom atendimento, consultoria na escolha do presente e requinte das embalagens No caso dos chocolates os cuidados essenciais estão na conservação no ponto de vendas (a maioria dos itens estão expostos em potes de vidro tampados), acondicionamento e transporte. Por isso a importância de uma embalagem não apenas visualmente agradável no ponto de vista estético, 


\begin{tabular}{|l|l|}
\hline & $\begin{array}{l}\text { mas também funcional e resistente. O chocolate deve ser consumido à } \\
\text { temperatura ambiente (ideal até 23 C e no caso de trufas, 16o C). Quanto } \\
\text { aos cafés, a empresa faz questão de manter em seus estoques duas ou três } \\
\text { marcas top de linha e servi-los sempre acompanhados de água com gás e } \\
\text { alguns pequenos confeitos de chocolate. }\end{array}$ \\
\hline $\begin{array}{l}\text { Motivações / fatores na } \\
\text { decisão de compra }\end{array}$ & $\begin{array}{l}\text { Produtos de qualidade, inéditos ou exclusivos no mercado, bem embalados, } \\
\text { visualmente impactantes e de boa relação custo-benefício. Preza-se o bom } \\
\text { atendimento, a atmosfera tranquila da loja (média luz, tons marrons, estilo } \\
\text { rústico, porém requintado) e a possibilidade de consumir no local (nas } \\
\text { mesas), como em um autêntico café europeu. } \\
\text { Assinalar um } \\
\text { ( ) Preço } \\
\text { ( ) Estética } \\
\text { ( ) Características técnicas } \\
\text { (x) Outros: novidade, inovação, diferencial }\end{array}$ \\
\hline
\end{tabular}

Quadro 6-Mercado - utilizador do produto

- Comunicação

Aparência e imagem esperada do produto
Ser amplamente conhecido no mercado como ícone de um produto sofisticado, identificável com seu público-alvo, valorizado pela força de sua marca e seus valores agregados, visualmente diferentes dos concorrentes e repleto de simbologias que remetam ao romantismo, ao clássico, ao bom gosto, ao especial e ao luxuoso, sem, no entanto, deixar de ser acessível e com boa relação custo-benefício

Quadro 7-Mercado - comunicação

- Nível de preços Posição do preço em relação à concorrência

Em relação aos chocolates, seus preços são aplicados de acordo com a origem do produto (nacional ou importado), seu peso em gramas, nível da embalagem (comum ou para presente), artigo trabalhado (decoração ou recheio dos confeitos). Os cafés e afins também têm seus preços ditados pela natureza da matéria-prima, quantidade servida e acompanhamentos. De uma maneira geral, o preço é compatível com o seu público-alvo (classe A e B).

Quadro 8-Mercado - nivel de preços

\section{- Embalagem e manuseio}

De origens artesanal ou industrial, as embalagens procuram ser específicas para aplicação. Podem ser de material plástico, papel ou papelão, com funções de armazenamento, empilhamento, transporte e presentes, respeitando as características do produto embalado. No caso do chocolate, além de apresentarem o produto devem conservá-lo íntegro e sua estrutura, cores, formas, aromas e sabores.

Quadro 9-Mercado - embalagem e manuseio

\section{Especificações}

- Funções que o produto deve satisfazer / função principal - funções secundárias Função principal (objetiva): Chocolate: Comer, apreciar e satisfazer vontade. Café: beber, complementar refeição, aquecer-se.

Função secundária (subjetiva): Chocolate: presentear com originalidade, satisfazer sensações gustativas + visuais + afetivas. Café: Encontro com amigos, satisfazer necessidade de cafeína (prazer), ocupar o tempo e apreciação através de degustação (paladar). 


\section{Processos produtivos da empresa}

- Capacidade instalada / necessidade de terceiros

Nas dependências da loja existe a área de cozinha onde os itens são produzidos. A matéria-prima é adquirida de bons fornecedores (fábricas nacionais e estrangeiras com excelente reputação) e ali manipulada transformando-se nos produtos que, posteriormente, serão embalados e postos à venda. No caso de processos específicos e mais complexos é a proprietária quem trabalha o chocolate, pois possui farta experiência nesta técnica. Na produção de outros itens, em que a práxis é mais simples, existe a participação direta de suas funcionárias.

Em relação aos produtos industrializados (prontos), são adquiridos e expostos à venda nas gôndolas da loja, disponíveis à apreciação e ao alcance do consumidor.

Possui apenas um ponto de venda e não trabalha com revendas. As entregas em curta distância são realizadas pelos próprios funcionários; para maiores as realiza via mototáxi. Para grandes demandas, opta pelo sistema de encomendas e orienta os consumidores a fazerem seus pedidos previamente, no caso de eventos ou datas específicas.

Nota: a empresa possui uma gôndola com seus produtos em um dos principais hotéis da cidade.

\section{Custos}

- Custos ou limitações

A proprietária da "Empresa X" ressalta que a sua limitação orçamentária está diretamente ligada ao faturamento. Dentre suas necessidades, a mesma confessa que precisa procurar, a todo momento, alternativas cujas vendas de produtos assegurem a cobertura de seus custos operacionais principalmente fora das datas consideradas de "pico" como Páscoa, Dia das Mães, Dia dos Namorados e Natal. Porém, não teme investir ainda mais, desde que os recursos financeiros sejam alocados em ações que realmente tragam benefícios concretos e perenes.

\section{Oportunidades e restrições}

Pontos fortes da empresa:

- Alta Qualidade de seus produtos e serviços;

- Comercio de produtos importados além dos nacionais já conhecidos;

- Predomínio dos públicos das classes A e B, que necessariamente, não se prendem às questões de preço baixo para decidirem a compra e sim à qualidade e aos benefícios subjetivos do produto adquirido;

- Excelente localização (área central da cidade);

- Know-how da proprietária no lido com seus produtos;

- Ponto comercial bem decorado e com bons equipamentos;

- Atendimento personalizado (você conversa com a proprietária que lhe dá a melhor orientação para suas compras);

- Busca incessante por inovações: sempre atualiza, pesquisa e trabalha novas configurações de processos para a produção e desenvolvimento de novas receitas, principalmente em suas trufas e cafés;

- Pré-disposição para investir em publicidade e alta receptividade a ideias alusivas à marketing e propaganda. Porém sinaliza sempre que as propostas devam ser bem 
fundamentadas e esclarecidas. Todas as propostas passam pelo seu crivo pessoal, onde seu gosto é imperativo, antes de serem cogitadas à implementação.

Pontos fracos da empresa

- Não possui um plano estratégico de Marketing e Design consistentes;

- Não possui site na Internet;

- Não oferece estacionamento próprio a seus clientes;

- Não há um padrão nas embalagens de seus produtos, principalmente nos itens destinados a presentes;

- Embora procure oferecer bom atendimento e produtos de qualidade, ainda não tem sua imagem consolidada no mercado como uma opção fortemente reconhecida no momento de se tomar um bom café ou presentear com chocolates.

\section{Estratégias da empresa}

Desde que foi inaugurada (há dois anos), não realizou grandes e maciços investimentos em divulgação e peças gráficas. Possui apenas dois folders em dois formatos distintos, ilustrados com fotos de seus produtos e com dados da loja. Recentemente realizou uma campanha institucional composta de um sistema de outdoors com duração de 15 dias, mas segundo a proprietária, que não trouxe resultados satisfatórios.

\section{Análise dos Resultados}

As proposições a seguir resumem o panorama detectado pela ferramenta de diagnóstico aplicado visando a obtenção de uma profundidade maior, tanto no volume quanto no teor das informações tidas como apontadores e geradoras de subsídios para as ações que irão buscar a supressão dos problemas detectados e o incremento de maior vitalidade a seus acertos.

A Empresa $X$ está há dois anos no mercado local, com apenas um ponto comercial estabelecido na área central da cidade. Mantém um público definido pela sua proprietária como pertencente às classes $A$ e $B$, ambos os sexos e de idade compreendida entre 20 e 50 anos (predomínio de jovens empresários). Comercializa produtos à base de chocolate nacional e importado para consumo instantâneo ou para presentes. Também mantêm uma cafeteria que oferece cafés considerados "Premium" e acompanhamentos diversos como salgados e doces.

A proprietária, mesmo demonstrando domínio na arte de manipular chocolates e presentes, mantendo sua loja em um ponto comercial bem decorado, de ambiente agradável na avenida mais movimentada da cidade e com bom atendimento, observa que ainda não conseguiu a projeção que espera para sua empresa: ser referência em presentes finos em chocolate e cafeteria de qualidade na cidade, uma vez que considera possível se chegar a este patamar, por tudo o que é capaz de oferecer.

A Gestão do Design neste caso deve então ser aplicada com foco no Marketing, otimizando a comunicação da Empresa $X$ com o mercado, apresentando seus diferenciais e qualidades, conquistando novos clientes ao mesmo tempo em que perpetua a excelente relação que já mantém com os atuais. A prioridade está em concentrar esforços em ações eficazes, advindas dos acertos nas tomadas de decisões e que propiciem à sua marca, a força mercadológica almejada. 
Como ponto-chave tem-se a informação de que o público que frequenta a loja o faz em busca de novidades. Exclusividade, ineditismo, diferenciais e satisfação estética são os valores mais procurados em seus produtos, principalmente nos destinados a presentes. A inovação é um critério que deve estar intrínseco em todas as fases, processos e ações estratégicas, táticas e operacionais. É o "combustível" de todos os seus procedimentos e o principal fator de decisão para o consumidor no momento da compra. Neste caso, o conceito de valor supera o fator preço.

O resultado esperado, em função das ações de GD é, portanto, a consolidação da marca e a construção de sua identidade como empresa referência em chocolates especiais que ofereça novidades e ótimas sugestões para presentes, propiciando excelência em atendimento e momentos agradáveis acompanhados de um bom café. As ações de Gestão de Design propostas devem intervir em uma realidade em que se observa estagnação nas vendas, insuficiência de projeção mercadológica e a carência de uma sistematização de procedimentos fundamentados que a conduzam a um melhor desempenho na esfera commercial.

\section{Proposição de Ações de Gestão de Design}

Apresenta-se, a seguir, problemas e sugestões de nível básico, de ações administrativas com foco na Gestão de Design e no Marketing, separando-se as prioritárias, com base nos problemas detectados no diagnóstico em relação ao Ponto de Venda (PDV), sintetizados no quadro abaixo:

\section{Ações prioritárias}

Em relação ao ponto de venda:

\begin{tabular}{|l|l|}
\hline Problemas detectados & Sugestões \\
\hline $\begin{array}{l}\text { Comunicação externa lateral inexistente. Para quem } \\
\text { trafega pela avenida de seu logradouro, sentido } \\
\text { bairro-centro não há acesso à comunicação visual da } \\
\text { loja. }\end{array}$ & $\begin{array}{l}\text { Instalação de um totem ou placa indicativa com a } \\
\text { face em 90o em relação à avenida. }\end{array}$ \\
\hline $\begin{array}{l}\text { Banner plástico externo com problemas de } \\
\text { visualização e instalação (cai com o vento). }\end{array}$ & $\begin{array}{l}\text { Criação de um suporte fixo para o banner utilizado-o } \\
\text { mais como peça de anúncios promocionais. }\end{array}$ \\
\hline $\begin{array}{l}\text { Janela ou vitrine? } \\
\text { Definir. Se janela, propiciar melhor iluminação e } \\
\text { proteção solar para os clientes no interior da loja e } \\
\text { se for vitrine potencializá-la com boa iluminação e } \\
\text { decoração favorável à exposição dos produtos. }\end{array}$ \\
\hline $\begin{array}{l}\text { Perfil básico do ramo de atividade não muito } \\
\text { evidente na loja. Será um ponto comercial de vendas } \\
\text { aberto e receptivo ou público em geral (varejo) ou } \\
\text { point VIP de vendas com atendimento seleto? }\end{array}$ & $\begin{array}{l}\text { Definir o conceito do negócio / posicionamento e } \\
\text { adequar a loja para este. }\end{array}$ \\
\hline
\end{tabular}

Quadro 10 -Problemas e soluções prioritárias em relação ao ponto de venda 
Em relação à equipe:

\begin{tabular}{|l|l|}
\hline Problemas detectados & Sugestões \\
\hline Bom atendimento porém sem grandes diferenciais. & $\begin{array}{l}\text { Treinar equipe par atendimento diferenciado e } \\
\text { personalizado. Atenção, zelo, respeito e agilidade. }\end{array}$ \\
\hline Motivação, abertura e diálogo. & Envolver a equipe no processo de vendas e motivá-la. \\
\hline $\begin{array}{l}\text { Conhecer o negócio como um todo, os produtos e } \\
\text { compreendê-los. }\end{array}$ & $\begin{array}{l}\text { Treinamento para oferecer a melhor orientação para o } \\
\text { cliente otimizando as vendas. }\end{array}$ \\
\hline Adquirir a linguagem do cliente. & $\begin{array}{l}\text { Foco na atenção total ao cliente, compreendendo suas } \\
\text { necessidades, potenciais de compra, apresentar } \\
\text { novidades, efetuar embalagens de acordo com seus } \\
\text { gostos e desejos. }\end{array}$ \\
\hline
\end{tabular}

Quadro 11 - Problemas e soluções prioritárias em relação à equipe

\section{Ações de Gestão de Design}

De acordo com os dados levantados pelo briefing e pela profundidade das informações obtidas por meio do diagnóstico, foram enumeradas, abaixo, vinte e uma ações para a empresa, divididas em ações de design e de marketing. Elas demonstram, além de outras questões, a carência ou até mesmo inexistência de atitudes vitais para a manutenção efetiva de sua marca e sua consolidação no mercado. Cabe ressaltar que nas ações de marketing, as peças gráficas devem ser definidas pelo Design, a fim de se manter a unidade visual e a imagem de marca bem definidos, reforçando os valores apontados na estratégia. São elas:

\section{Ações iniciais}

1 Utilizar métodos sistematizados para conhecer melhor seus clientes. Quem são, o que fazem quando e como consomem mais, como, por exemplo, um mapeamento das estatísticas de vendas ou pesquisas de opinião exporádicas no ponto de vendas.

2 Definir um posicionamento consistente (clareza na proposição de valor) que traduza a filosofia da empresa a ser transmitida por todas as manifestações visuais .

3 Manter de forma intensa o foco no público-alvo.

4 Estabelecer ações para a prospeç̧ão de novos clientes, sem, no entanto, descuidar dos atuais.

5 Manter um mailing (cadastro de clientes) atualizado e consistente, em quantidade e qualidade, com possibilidade de envio de malas-diretas via web (através de e-mail personalizado da empresa, por exemplo) ou de maneira impressa (pelos correios).

6 Organizar os produtos: devem estar todos classificados, mapeados e divididos em categorias. Do ponto de vista administrativo, precisam ter seus custos unitários e margem de lucro bem definidos. Também devem ser identificados os "carros-chefes" de cada setor e aqueles que ainda não alcançaram a divulgação necessária e trabalhá-los nesta esfera.

\section{Ações de Design}

Estabelecer ações que transmitam ao consumidor a imagem desejada pela empresa, como por exemplo:

7 Padronizar a identidade visual dos produtos, a fim de identificar e transmitir visualmente os valores estabelecidos pela empresa. 
8 Investir frequentemente no ponto de venda, buscando manter um visual cada vez mais atraente, convidativo e que chame a atenção de consumidores potenciais, tomando-se o cuidado de não estigmatizá-lo como "lugar de produtos caros e inacessíveis".

9 Inserir Tags nos produtos: etiquetas ou cartõezinhos identificando e valorizando a marca, com dados que atestem a origem, que apresentem as características essenciais do produto e que facilitem eventuais contatos entre os consumidores e a loja.

10 Criar e manter um site institucional com possibilidade de anúncios promocionais em concomitância com a loja publicando ferramentas de diálogos e enquetes, com o objetivo de captar o perfil e as aspirações dos consumidores internautas.

\section{Ações de marketing}

Estabelecer ações previamente levantadas e classificadas, de acordo com as prioridades da loja, em função de dados reais e consistentes, visando procedimentos e projetos em curto, médio e longo prazo, como, por exemplo:

11 Criar novas necessidades de consumo (novos produtos) a fim de manter as vendas aquecidas sempre procurando informar o cliente que há lançamentos disponíveis.

12 Estar presente de forma ativa, maciça e dinâmica na Internet.

13 Divulgar em mídia impressa, não apenas nas proximidades da loja, mas também e de maneira intensa nas imediações de lugares onde há grande circulação de público com o perfil de sua clientela.

14 Anunciar em mídias como jornais, rádios FM, revistas sociais, listas telefônicas, TVs locais, etc., explorando-se as sazonalidades.

15 Oferecer degustação visando proliferar a cultura de se apreciar chocolates. Pode ser feita em frente à loja, em dias previamente estabelecidos e sistematizados ou em locais específicos, como shoppings, feiras, eventos, universidades, entre outros, com equipe uniformizada oferecendo produtos e distribuindo pequenos tabletes de chocolate com cartões publicitários anexados.

16 Participar direta e efetivamente em eventos que costumam reunir pessoas das classes A e B como convenções em hotéis, feiras, congressos profissionais, etc.

17 Realizar pesquisas de mercado e de opinião no ponto de vendas periodicamente, realizando coletas de informações com vistas a direcionar os esforços de marketing na satisfação das necessidades dos clientes através de pequenos questionários preenchidos no ato da compra ou pela web.

18 Focar clientes potenciais oriundos do público-alvo, como por exemplo gerentes de bancos, donos de concessionárias, imobiliários, médicos, advogados, dentistas, arquitetos, altos escalões de funcionários públicos, entre outros, Ihes convidando e incentivando a realizarem reuniões de negócios e pequenos meetings na loja. Deixar claro que a Empresa $\mathrm{X}$ oferece, além do bom café e do ponto bastante agradável, acesso a web (wi-fi zone).

19 Realizar promoções nas épocas de baixo movimento: criar e divulgar promoções ou pequenos eventos dirigidos aos clientes VIP para incrementar as vendas nos períodos de "vale".

20 Anunciar em comerciais de TV: inserções publicitárias em horários nobres ou até mesmo a presença da proprietária em programas específicos.

21 Monitorar as ações da concorrência, identificando quem, de fato, são os atuais concorrentes, onde estão, o que fazem, e quais os seus diferenciais e equivalências. 
Verficadores posteriores às ações

Após a adoção e efetivação das ações propostas no item anterior, convém que procedimentos de análise e monitoramento dos resultados sejam realizados a fim de se constatar não apenas a eficiência de cada uma delas, mas a eficácia do conjunto, de como e de quanto este plano poderá trazer benefícios diretos e indiretos para a empresa. Para este procedimento sugere-se a aplicação de duas ferramentas: uma análise fundamentada na Gestão do Design Aplicada sugerida por Merino (2008) e um monitoramento com base na ferramenta Balanced Scorecard (BSC), proposta por Kaplan (1998).

Análise segundo a gestão do design aplicada

Merino (2008) enfatiza que esta instância para a Gestão de Design busque o monitoramento, o aperfeiçoamento, as repetições e as eventuais manutenções que se fizerem necessárias ao Plano de ações e que se considere:

- O Design para racionalização (valores internos): verificar como a proprietária vem lidando e equacionando questões como tecnologias de processos de confecções de seus produtos, os valores manifestados por seus clientes, consumidores e usuários (qualidade, graus de satisfação e de necessidades atendidas, etc.) e como lida com normas e procedimentos operacionais de seu negócio.

- O Design para diferenciação (valores externos): constatar a existência, frequência e eficácia de suas pesquisas na coleta de feedbacks e informações de seus clientes, identidade, personalidade, inovação e compreensão de suas importância, diferenciais e qualidade perante o mercado, níveis de necessidades atendidas pelos seus produtos (primárias: comer chocolate, tomar café ou secundárias: presentear, reunir-se com amigos, relaxar).

Após a verificação da realidade atual da empresa, a adoção de procedimentos com bases nas ações adotadas e a coleta das respostas do mercado, através, principalmente, de pesquisas e saldos financeiros, é que se passará para a esfera das análises propriamente ditas. Nesta fase procura-se mapear os resultados diretos (aumento de vendas e reconhecimento por parte do mercado) e indiretos (consolidação da marca e compreensão pelo mercado de seus valores subjetivos). Analisa-se então:

- Passado: como era, como agia, o que mudou, como e que custos e benefícios foram suprimidos ou incrementados em relação às suas antigas práxis de mercado;

- Presente: Como a empresa se vê, como se avalia e percebe suas ações no dia a dia. Quais são as tecnologias, posturas, filosofias e critérios que hoje se vale para dar continuidade a seu trabalho, valendo-se da Gestão de Design;

- Futuro: Quais serão seus novos passos, a curto, médio e longo prazo, o que deverá mudar, retirar ou acrescentar em seus produtos e serviços de maneira a manter-se firme no mercado e viabilizar com sucesso suas atividades.

Os resultados desta análise são geralmente classificados da seguinte forma:

- Não foram alcançados (fracasso/ subsídios para novas ações)

- Alcançados (projeções atendidas/ satisfatório)

- Superados (além do previsto/ êxito incorporado a seus processos)

- Divergentes (inesperados/ em outras instâncias/ novas potencialidades) 
Em relação aos resultados, é preciso que sejam equacionados de maneira séria e com propriedade. Excesso de pessimismo ou otimismo pode levar a rumos muitas vezes desagradáveis e comprometer os negócios. Sugere-se cautela nas suas análises e, no caso de superávit destinar parte dos lucros a novos investimentos em DNP, pesquisas e I\&D.

Considerando as etapas anteriores, deve-se averiguar os pontos fortes (potencialidades) e fracos (fragilidades) da empresa e alocar recursos disponíveis (capital/ conhecimento) a fim de desenvolver suas potencialidades e consolidar seus valores vigentes. Em relação a seus pontos fracos, busca-se a origem dos problemas (foco na solução) para amenizá-los o mais rápido possível respeitando-se suas realidades e eventuais limitações (criatividade).

Análise segundo o Balanced Scorecard (BSC)

O BSC pode ser aplicado de maneira sintética na Empresa $X$, avaliando-se o desempenho de cada setor que a compõe, coletando dados e apontadores de resultados e classificando-os. Diante destes, pode-se propor melhorias com foco no fator humano e na comunicação horizontal (entre os setores) e não apenas vertical (fluxo hierárquico). Em linhas práticas, propõe-se que a empresa avalie e estimule toda a rede, desde o momento da compra da matéria prima (no caso, o chocolate), passando pela sua manipulação, exposição, venda e pós-venda, observando-se evoluções consideráveis em seus capitais financeiros, humanos, tecnológicos, mercadológicos, entre outros. A análise segundo o BSC, no entanto, depende do fator tempo, e está em processo. Pretende-se narrar a sua aplicação prática e os resultados obtidos em momento posterior.

\section{Conclusão}

Através dos procedimentos descritos neste artigo, deu-se o início à implementação de um processo de Gestão de Design na Empresa X. A aplicação de apenas um briefing tradicional, pelo teor sintético de suas questões, poderia não atingir a magnitude e a profundidade das informações necessárias a um diagnóstico mais preciso e consistente, principalmente que leve o gestor de Design aos porquês da marca em questão não ter ainda conquistado a fatia do mercado que almejou nestes dois primeiros anos de existência. Optou-se, então, pela aplicação de uma ferramenta de diagnóstico mais ampla e completa, cujos resultados deram importantes subsídios para o estabelecimento de ações em Marketing e Design consideradas vitais para a potencialização da marca da empresa em questão. Estas ações, de diferentes níveis e instâncias, por seu ineditismo e viabilidade, demonstram ser, de fato, os passos que conduzirão a marca da Empresa $X$ a galgar a projeção mercadológica e a consolidação de sua imagem tão esperadas.

Como a Gestão de Design é um processo dinâmico e ininterrupto, sugeriu-se, também, dois procedimentos para análise de resultados e manutenção do plano proposto (um protocolo de gestão de análise aplicada e um monitoramento via BSC) para que, a partir da leitura e interpretação dos apontadores de evolução da empresa, as ações possam ser continuamente re-implantadas, mantidas, reformuladas ou até mesmo suprimidas, se for 0 caso.

Com esta abordagem, ficou nítida a importância de métodos para a eficaz intervenção do gestor de Design, especificamente perceptível no diagnóstico utilizado, seja em qual for a empresa ou instituição para a qual esteja atuando. Também ficou claro que o 
Design, com toda a sua complexidade, não pode se restringir a ações táticas e operacionais, como forma de remediar problemas cuja natureza aparentam ser de causas conhecidas ou triviais, quer para o designer que o pratica, quer para o empresário que o contrata.

É sabido que marca não se restringe apenas ao elemento gráfico que dá origem a todo projeto de identidade visual. Marca é muito mais. Ela transparece o DNA da empresa, ou seja, de onde vem todas as políticas, formas de trabalho, público-alvo, características de operação, situação de organização externa e interna, graus de investimentos, entre outros. As proposições estabelecidas neste artigo sinalizam que o Gestor de Design para a Empresa $X$ deve ser prioritariamente um gestor de marca, não apenas zelando pela manutenção de sua imagem junto ao mercado, mas contribuindo de fato para que todos os setores e segmentos desta estejam em total consonância com a identidade corporativa pretendida. $A$ marca deve estar não apenas visível, mas totalmente assimilada nos produtos, nos processos de produção, no atendimento, na política de preço, compreendida e valorizada no íntimo de sua equipe e em todos os seus níveis. Para se construir e consolidar uma marca, é necessário coletar todas as informações possíveis sobre o negócio, sobre o segmento em que atua, a posição a ser conquistada, os valores a serem passados ao consumidor e seus hábitos e de que forma eles serão transmitidos, respondendo às necessidades, desejos gostos e conveniências desse consumidor.

A Gestão de Design, portanto, é um campo de conhecimento muito vasto e cuja multidisciplinaridade lhe dá a propriedade de oferecer à organização que a implementa uma visão estratégica, mais completa, dinâmica e acertada de si própria e do bioma em que está inserida. Espera-se que, no caso da Empresa $X$ suas expectativas não sejam apenas correspondidas, mas superadas, durante toda sua trajetória.

\section{Referências}

AACKER, D. A. O Paradigma emergente. D2B Design to Branding Magazine, São Paulo, ano 13, n. 13, p. 18-23, dez. 2007.

DRUCKER. P. Inovação e espírito empreendedor. São Paulo: Pioneira, 1987.

GIL, A. C. Como elaborar projetos de pesquisa. 4. ed. São Paulo: Atlas, 2002.

KAPLAN, R. Balanced Scorecard. HSM Management, Barueri, n. 11, p. 120-126, nov./dez. 1998.

KOTLER, P.; AMSTRONG, G. Princípios de marketing. 12. ed. São Paulo: Pearson Prentice Hall, 2007

CENTRO PORTUGUÊS DE DESIGN. Manual de gestão do design. Porto, 1997.

MARTINS, R. F. F.; MERINO, Eugenio Andrés Dias. A gestão de design como estratégia organizacional. Londrina: EDUEL, 2008.

MERINO, E. A. D. Gestão de design na prática: do diagnóstico à definição de estratégias de design.. Porto: Centro Português de Design, 2008. (Adaptado do manual de gestão do design, 1997).

MOZOTA, B. B. Design management. Paris: Éditions d'Organization, 2002. 
SCHIMIDT, A. O. Uma contribuição ao estudo da evolução dos modelos gerenciais frente aos desafios impostos pela globalização. 97f. Dissertação (Mestrado em Engenharia de Produção) - Programa de Pós-graduação em Engenharia de Produção, UFSC, Florianópolis, 2001.

YIN, R. K. Estudo de Caso: planejamento e métodos. 2.ed. Porto Alegre: Bookman, 2001 